\title{
Study on the Application of Pad Class Based on U-learning
}

\author{
Caixia Wang, Qian Wang \\ Shandong Jiaotong University, Weihai, Shandong
}

Keywords: Pad Class; U-learning; Active learning

\begin{abstract}
Based on the U-learning, the paper focuses on the application of Pad Class (PresentationAssimilation-Discussion) in maritime business and maritime law course. In the experiment, students completed the transformation from passive learning to active learning. In addition, they learned how to find problems, think independently, cooperate and communicate effectively with others, which were beneficial for students' lifelong development. What is more, in order to adapt to students' Ulearning, the network resources of maritime business and maritime law course were optimized.
\end{abstract}

\section{Introduction}

Classroom is the main place of teaching activities; classroom quality is a decisive factor in teaching quality. In the network age, the channels and ways of college students' acquiring knowledge have been diversified. In terms of diversity, interest and timeliness, the knowledge that teachers taught cannot be compared with the network. A college class often has two or three consecutive periods. For students growing up in the age of information fragmentation, it is more difficult to keep up with teachers' lectures for a long time. Humorous and performance-style lectures can attract students, but few teachers can do it. The reality is that the students' learning model has changed radically. The first stage of traditional learning methods, it mainly relies on textbook to learn, the second stage is based on internet learning, the third stage is based on mobile internet and mobile terminal learning. And the present stage IV: U-learning model.

\section{U-Learning}

U-Learning (ubiquitous Learning), also known as seamless learning, pervasive learning, is a constant communication, is anyone can be anywhere, any time to obtain any information required. Network education and Network learning are new channels for colleges and universities nowadays. It can better cater to the characteristics of college students. Powerful information systems and platform construction provide strong support for education. U-Learning aims to enable students to achieve more effective lifelong education in an educational environment where they can learn from any terminal, especially the network. The impact of the Internet and new media and the changes in student learning patterns has led teachers to rethink how to teach students to learn instead of forcing them to learn. In U-learning environment, as long as students take the initiative to learn, anytime and anywhere they can learn. On the contrary, even if there is a good resource, students who do not want to learn can not achieve the purpose of acquiring knowledge.

\section{Pad Class}

At present, the research on how to improve students' learning efficiency is mainly focused on the reform of teaching methods, such as traditional teaching, discussion teaching, mixed teaching based on flipped classroom, etc. These teaching methods are proposed and reformed from the perspective of teachers, trying to change the learning efficiency of students through teaching changes. Pad Class is a new idea that concentrates on teaching the student the learning process. The core idea of the class is to allocate half of the classroom time to the teacher, while the other half of the time is allocated to the students for interactive learning in the form of discussion.

The starting point of Pad Class is to arouse the enthusiasm of the students, to allow the students 
to participate actively. Teachers must give up some of the classroom time to the students to control, leading to form a teacher-student "Pad" classroom pattern. Pad Class divides the teaching into three processes which are separated clearly in time, for lectures (presentation), for internal absorption (assimilation) and for argument (Discussion). The framework of Pad Class is shown in figure 1.

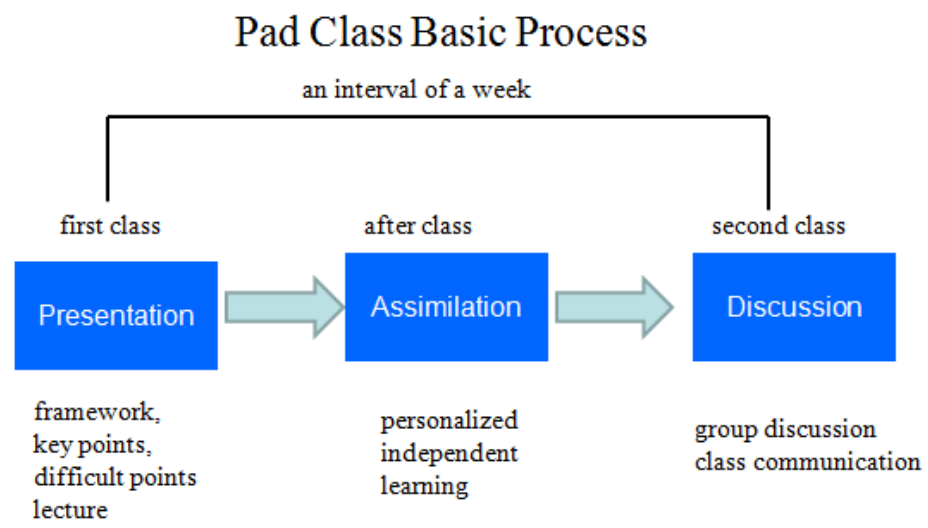

Figure 1 The framework of Pad Class

The key innovation in the Pad Class is the division, teaching and discussion time staggered not in a class, so that students have a week after class to arrange their own learning and engage in personalized absorption. In the long run, Pad Class model can not only promote students' ability to master and apply their knowledge flexibly, but also inspire students' enthusiasm for learning and produce a continuous learning power. At the same time it helps students to establish the confidence to express their ideas in language, to train students to actively communicate and solve problems. By this way, students complete the transformation from the classroom "object" into the "subject", from "passive learning” to "active learning”.

Zhang Xuexin [1] introduced Pad Class practice conducted in sophomore students. Questionnaire survey after the experiment showed the effectiveness of Pad Class. Ben Zhihong [2] discussed Pad Class being applied to ideological and political course in universities and stated that Pad Class can reduce the burden of teachers' mechanical teaching in ideological and political course, and realizing the change of teachers' role to "double Division”. Wang Fa, Wang Ruijin, etc. [3] carried out Pad Class in Special English for the Marine Engineering by combing lecture with discussion. Du Yanfei, Zhang Xuexin [4] explored the practice of Pad Class and reflected on the reform of classroom teaching mode in universities. Shi Mengxi, Ma Jing [5] studied the diversity of teachers and students' roles in Pad Class. The roles of teachers and students change with the changes of teaching link, teacher is no longer a simple knowledge imparter, students are no longer passive followers. The pluralism of teacher-student role provides the possibility for the positive interaction between teachers and students, and also provides a new way to improve the quality of classroom teaching.

\section{Experiment Procedures and Experience Gained}

Combining the reform of credit system and the application of network teaching platform in Shandong Jiaotong University, Pad Class “maritime business and maritime law” experiment was carried out in 2015 grade students who majored in navigation technology and 2016 grade students who majored in maritime management for a semester. It instructed students to learn step by step.

The experiment mainly includes the following three processes:

(1) The Pad Class pre-class teaching design accords with the students' cognition and helps the students to learn how to "preview". The homework assigned before the discussion class is crucial in Pad Class. Pre-class task/job design that meets students' cognition includes the following basic contents:

Firstly, there is a clear requirement. For example, read the textbook Page 5-8, answer questions 
1,2 and 3. Secondly, devise the task with different difficulty levels. For example, the first question is simple, and the answer can be found directly in the textbook. The second question is to be discussed after consideration. The third is the application of cases to solve specific problems. In addition, each homework has a summary of the discussion, and "Light, Test, Help" is a good form.

"Light" is to list the contents that you feel most deeply, benefit the most and appreciate in the course of learning, at least one, more unlimited. "Test" is to list the places that you understand, but think that others may be confused, to challenge others, at least three, more unlimited. "Help" is to make a list of questions that you don't understand and ask for help when discussing, at least three, more unlimited.

"Light, Test, Help" places emphasis on the application of knowledge and divides students' independent study results into three parts: the most valuable knowledge students got, the knowledge students mastered on their own by working hard, the things students tried hard but still can't understand. It encourages students to express themselves in the form of questions.

(2) The real application of Pad Class based on students' U-Learning model to help students learn to "discuss."

In the "preview" stage, with the help of U-Learning environment, students integrate and use the resources such as online and offline courses to effectively complete the task/homework before class. The students' discussion stage is the key of the classroom link. There are 4 links in the discussion of Pad Class: group discussion, teacher spot check, free questioning, teacher's summary. In the group discussion, the whole class is divided into 5-6 groups, 4-6 people in each group. In the discussion stage, teacher makes the discussion task clear, group leader is responsible for organization discussion, each student shares his or her view through the "Light Test help". And eventually, each group formed the group's "Light Test Help". Through the design of these links, to help students learn to "discuss".

(3) To establish a new learning evaluation system adapted to the Pad Class, so that students have the motivation to "self-study"

Pad Class emphasizes on the division of the classroom, the teacher and the students each half time. Students have more opportunities to learn by themselves and exchange discussions. In the traditional evaluation system, the final exam grade accounts for more than $60 \%$, even $70 \%$ of students' total mark, students regular grade accounts for less than $40 \%$, even $30 \%$ of students' total mark. The main composition of student's regular grade is attendance and a limited number of assignments. In the new learning evaluation system, the higher proportion of regular grade is raised to $50 \%$, so that students have the motivation to study. In the Pad Class, UMOOC, Moso Teach and other network platforms are used to achieve the evaluation of students' daily learning experiences, record students' class performances and complete the evaluation of student's pre-class homework.

\section{Conclusions}

Through the application of "Pad Class", the students are taught the learning processes: lecture (teaching the key content)- self-study (completing the task/homework after class)- Discussion (group discussion in Class)-Summary (reading notes). By the application of Pad Class, students learn to find problems, think about things independently, cooperate with others to explore problems, conclude and innovate questions, which are beneficial for students' lifelong development. Taking the network teaching platform as an opportunity, through this experiment, we optimize the network resources of the course "maritime business and maritime law", so that students have sufficient learning resources when they study independently.

In the actual operation of Pad Class, we also encountered some problems, which need to be improved, for example: in large classes, more than 100 students are divided into almost 20 groups with one group of 6 students. Recording each student's classroom performance turns very hard. At the same time, in the process of teacher spot checks, some of the groups that have not been randomly tested are comparatively not concentrated on the discussion. Therefore, it is more difficult to apply Pad Class in large classes than the small ones. 


\section{References}

[1] Zhang Xuexin Pad Class: New Exploration of College Classroom Teaching Reform [J]. Fudan Education Forum, 2014,12(05):5-10

[2] Ben Zhihong Pad Class: Exploration on the Reform of Classroom Teaching Mode of "ideological and political course” in Universities[J]. Shanxi Normal University Newspaper (Social Science edition) 2016. 06

[3] Wang Fa, Wang Ruijin, etc. The Practice and Exploration of Pad Class in Special English for the Marine Engineering [J]. Education Modernization 2017, 02

[4] Du Yanfei Zhang Xuexin Pad Class: Practice and Reflection on the Reform of Classroom Teaching Mode in Universities [J] Continuing Education Research 2016.03

[5] Shi Mengxi, Ma Jing Pad Class: The Study on the Diversity of Teachers and Students' Roles Xueyuan 2016. 08 